
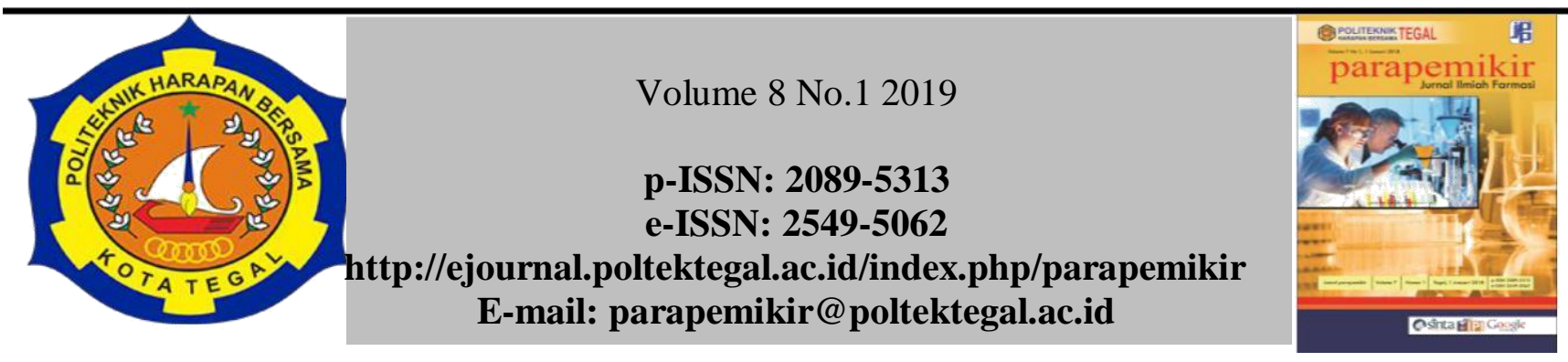

\title{
SIX SIGMA UNTUK PERBAIKAN LAYANAN RESEP DI RS X KOTA SEMARANG
}

\author{
Sri Suwarni ${ }^{1}$, Metrikana Novembrina ${ }^{2}$ \\ ${ }^{12}$ Akademi Farmasi Nusaputera \\ Email : warnisutanto@gmail.com,srisuwarni@akfarnusaputera.ac.id
}

\begin{tabular}{l}
\hline Article Info \\
Article history: \\
Received October \\
2018 \\
Received in \\
revised form \\
Desember 2018 \\
Accepted Januari \\
2019 \\
Available online \\
January 2019 \\
\hline Kata kunci: \\
Defect, medication \\
error, sigma, yield
\end{tabular}

Keywords:

Defect,

medication error,

sigma, yield

\begin{abstract}
Abstrak
Six sigma merupakan metode perbaikan yang berfokus pada output perbaikan mutu bebas dari defect dan bernilai penting bagi pelanggan. Berdasarkan standar pelayanan kefarmasian di Rumah Sakit, bahwa pada setiap tahap alur pelayanan resep dilakukan upaya untuk pencegahan terjadinya kesalahan pemberian obat (medication error). Tujuan penelitian ini untuk mengetahui kinerja pelayanan resep di instalasi farmasi rawat jalan dengan menghitung kejadian yang berpotensi medication error dianalisis dengan Six sigma digunakan untuk menentukan prioritas output perbaikan mutu yaitu penurunan defect pada pelayanan resep. rancangan penelitian deskriptif observasional, populasi penelitian ini adalah pasien farmasi rawat jalan, tehnik pengambilan sampel dengan metode probability sampling. Sampel dalam penelitian ini sebanyak 150 resep. Menggunakan instrumen ceklist lembar observasi penghitungan kejadian medication error. Model pemecahan masalah dalam metode Six Sigma terdapat 5 tahapan yaitu perumusan (define), pengukuran (measure), analisis (analyze), tindakan perbaikan (improve), dan kontrol (control). Nilai kinerja pelayanan resep nilai, Yield $=92,98 \%$, defect $=6,54 \%$, artinya kinerja pelayanan resep unit farmasi rawat jalan RSI Sultan Agung yang masih memberikan peluang munculnya potensi medication error sebesar $6,54 \%$. Niai sigma 2,146 maka masih dibutuhkan perbaikan pada kinerja pelayanan resep. Level sigma yang terhitung adalah prioritas perbaikan pada fase prescribing klinis, prescribing farmasetis, prescribing administratif, transcribing, dan dispensing untuk peningkatan keselamatan pasien.
\end{abstract}

\begin{abstract}
Six sigma is an improvement method that focuses on output quality improvement free from defects and important value for customers. Based on pharmacy service standards at the Hospital, that at each stage of the prescription service flow, efforts were made to prevent the occurrence of medication errors. The purpose of this study was to determine the performance of prescription services in outpatient pharmacy installations by calculating potential medication error events analyzed with Six Sigma used to determine the priority of quality improvement output, namely a decrease in defects in prescription services. observational descriptive research design, the population of this study were outpatient pharmacy patients, sampling techniques with probability sampling method. The sample in this study were 150 recipes. Using the instrument, check the observation sheet for counting medication errors. There are 5 stages of problem solving in the Six Sigma method, they are define, measure, analyze, analyze, and control. The value of the service performance prescription value, yield $=92.98 \%$, defect $=6.54 \%$, meaning that the service performance of prescription of RSI Sultan Agung outpatient pharmacy unit which still gives the opportunity for the emergence of medication error is $6.54 \%$. If the sigma 2.146 is still needed an improvement in the performance of prescription services. Calculated sigma levels are priority improvements in the phase of clinical prescribing, pharmacy prescribing, administrative prescribing, transcribing, and dispensing to improve patient safety
\end{abstract}


Sri Suwarni , Metrikana Novembrina, Vol 8 (1) 2019 pp 89-95

Alamat korespondensi:

Prodi DIII Farmasi Politeknik Harapan Bersama Tegal

Gedung A Lt.3. Kampus 1

Jl. Mataram No. 09 Kota Tegal, Kodepos 52122

Telp. (0283) 352000

p-ISSN: 2089-5313

E-mail: parapemikir_poltek@yahoo.com

e-ISSN: 2549-5062 


\section{Pendahuluan}

Metode six sigma adalah metode yang fokus pada bebas kesalahan (zero defect) dan mengurangi variasi serta mempercepat proses eliminasi waste sepanjang value stream sehingga akan memberikan nilai tambah (value added) ${ }^{[1]}$. Untuk mengatasi permasalahan pelayanan di Instalasi Farmasi diperlukan upaya pengendalian kualitas. Salah satunya adalah dengan menerapkan pendekatan Six Sigma yang merupakan strategi peningkatan kualitas yang berfokus pada pemenuhan persyaratan atau keinginan pelanggan. Penggunaan metode ini telah berhasil meningkatkan perusahaan dalam segi kualitas maupun keputusan strategik lainnya yang berfokus pada penurunan variasi proses dan penurunan kegagalan atau kecacatan/defect ${ }^{[2]}$. Pada penelitian tentang studi kualitas Pelayanan rawat inap rumah sakit dengan menggunakan metode six sigma untuk peningkatan Pelayanan kesehatan bagian rawat inap rumah sakit sebelum dan setelah implementasi Six Sigma ${ }^{[3]}$

Implementasi Six Sigma pada pelayanan bagian rawat inap Rumah sakit diharapkan akan mengalami peningkatan dari level sigma sehingga memenuhi standar Pelayanan Kefarmasian.

Evaluasi Mutu Pelayanan merupakan proses pengukuran, penilaian atas semua kegiatan Pelayanan Kefarmasian di Rumah Sakit. Kualitas Pelayanan meliputi: teknis Pelayanan, proses Pelayanan, tata cara/standar prosedur operasional, waktu tunggu untuk mendapatkan Pelayanan ${ }^{[4]}$.

Rumah Sakit Islam Sultan Agung adalah rumah sakit umum milik swasta yang berorintasi pada keselamatan pasien (patient safety) yang membutuhkan profit untuk sustainability sebagai organisasi penyelenggara Pelayanan kesehatan. Penelitian ini untuk mengetahui penilaian atas kualitas Pelayanan Kefarmasian menggunakan analisis Six Sigma dengan pendekatan Servperf dan temuan Kejadian Medication Error untuk Peningkatan Kinerja pada Pelayanan resep.

\section{Metodologi Penelitian}

Penelitian ini adalah dengan metode observasional secara prospektif. Data yang dikumpulkan berupa data kualitatif dan data kuantitatif. Data kualitatif berupa hasil wawancara terhadap pihak manajemen IFRS, sedangkan data kuantitatif diperoleh melalui observasi proses Pelayanan resep, data temuan Medication error. Pelayanan resep di farmasi rawat jalan di RS Islam Sultan Agung yang diobservai kemudian dianalisis dengan metodologi Six Sigma dengan metode pemecahan masalah DMAIC Pelayanan resep farmasi rawat jalan dengan six sigma (DMAIC) (Define, Measure, Analyze, Improve, Control) [5] untuk menentukan strategi perbaikan sehingga dapat memenuhi keinginan pasien yaitu patient safety. Resep-resep yang dilayani di Instalasi Farmasi Rawat jalan juga akan memberikan data dan informasi tentang medication error yang terjadi sebagai indikator Pelayanan kefarmasian. Lembar Observasi Resep untuk mengumpulkan data melalui observasi pada resep berupa: observasi medication error tahap prescribing, transcribing, dan tahap dispensing. Jumlah sampel resep yang adalah diambil 150 lembar.

Sampel yang dapat mewakili populasi diambil dengan metode probability sampling dari populasi pasien di instalasi farmasi rawat jalan

Defect yang dimaksud dalam penelitian ini adalah semua kejadian atau peristiwa dimana produk atau proses Pelayanan resep gagal memenuhi kebutuhan customer. DPMO (Defect per Million Opportunity) adalah ukuran kegagalan yang menunjukan kualitas proses Pelayanan resep farmasi rawat jalan RS Islam Sultan Agung yang tidak memenuhi keinginan customer per satu juta kesempatan. Pelayanan resep adalah dimulai dari penerimaan, pemeriksaan ketersediaan, pengkajian resep, penyiapan sediaan farmasi termasuk peracikan obat, pemeriksaan, penyerahan disertai pemberian informasi. Metode pemecahan masalah sebagai upaya untuk peningkatan terus meneruskan menuju target six sigma dengan zero defect yang dilakukan secara sistematik berdasar data. Berdasarkan hasil analisis atribut/ checklist medication error pada tahap-tahap Pelayanan resep (prescribing, transcribing dan dispensing). Nilai Yield berdasarkan pencapaian nilai Pelayanan resep farmasi rawat jalan RS Islam Sultan Agung (\% pencapaian).

klinik, kemudian tahap prescribing dan dispensing. Observasi Proses Pelayanan Resep yaitu Pelayanan Resep dimulai dari penerimaan, pemeriksaan ketersediaan, penyiapan Sediaan Farmasi, Alat Kesehatan, dan Bahan Medis Habis Pakai (BMHP) termasuk peracikan Obat, pemeriksaan, penyerahan disertai pemberian informasi. Pada setiap tahap alur Pelayanan resep dilakukan upaya pencegahan terjadinya kesalahan pemberian Obat (medication error) ${ }^{[4]}$. Observasi Pelayanan resep adalah proses pengamatan prospektif mulai dari pasien menyerahkan resep di unit farmasi rawat jalan RSI Sultan Agung sampai resep diracik/ disiapkan yaitu fase prescribing sampai dengan dispensing.

Dalam penelitian ini jumlah lembar resep yang diamati sebanyak 150 resep. Hasil Pengkajian resep adalah sebagai data karakteristik hasil pengkajian persyaratan administrasi resep adalah penjumlahan resep yang tidak lengkap kemudian di tentukan persentase dari potensi medication error.

\section{HASIL DAN PEMBAHASAN}

Analisis six sigma untuk menurunkan kejadian yang berpotensi medication error pada proses Pelayanan resep Pelayanan resep farmasi rawat jalan Rumah Sakit Islam Sultan Agung Kota Semarang. Menurut, six sigma merupakan metode perbaikan proses yang digunakan untuk memberikan produk dan Pelayanan yang lebih baik 
yang cukup akurat untuk memecahkan masalah dalam proses. [1] Penelitian ini bertujuan untuk membahas bagaimana rencana analisis six sigma dapat diterapkan, dalam penelitian ini dibuat langkahlangkah rencana penerapan six sigma di Unit Farmasi Rawat Jalan. Penelitian ini adalah mengobservasi resep Rawat Jalan RSI Sultan Agung Kota Semarang dengan lembar observasi untuk menemukan potensi kejadian medication error. Teknik analisa data primer yang sudah terkumpul yang bersifat kuantitatif dengan 5 (lima) parameter observasi yaitu tahapan Prescribing yaitu pengkajian resep/ skrining administrative, famasetis dan

Tabel 1. Karakteristik kelengkapan Administrative

\begin{tabular}{lrr}
\hline $\begin{array}{c}\text { Kelengkapan } \\
\text { Resep }\end{array}$ & \multicolumn{1}{c}{$\begin{array}{c}\text { Potensi } \\
\text { ME }\end{array}$} & $\begin{array}{r}\text { Akibat Potensi } \\
\text { Medication Error }\end{array}$ \\
\hline Nama & $0 \%$ & Salah Pasien \\
Umur & $0 \%$ & Dosis tidak tepat \\
Jenis kelamin & $0 \%$ & Salah pasien \\
Berat badan & $0,7 \%$ & Dosis tidak tepat \\
Nama dokter & $0 \%$ & Dosis tidak tepat \\
Paraf dokter & $0,7 \%$ & Penanggungjawab \\
Tanggal resep & $0 \%$ & Aspek legal telusur \\
Ruangan/unit asal & $0 \%$ & Aspek legal telusur \\
resep & & \\
\hline
\end{tabular}

Data Tabel 1 menunjukkan terdapat 2 kesalahan dari 150 lembar resep, bahwa potensi medication error yang minimal, ketidaklengkapan terjadi hanya pada berat badan pasien dan paraf dokter masing-masing ditemukan 1 resep. Hal tersebut terjadi karena sudah berjalannya e-prescribing dan dibantu dengan lembaran pengesahan terutama untuk pasien BPJS, data administrasi sudah harus terisi lengkap, sehingga kesalahan pada tahap ini dapat diminimalisir.

Tabel 2. Karakteristik kelengkapan farmasetis

\begin{tabular}{|c|c|c|}
\hline $\begin{array}{c}\text { Kelengkapa } \\
\text { n } \\
\end{array}$ & $\begin{array}{c}\text { Potensi } \\
\text { ME }\end{array}$ & $\begin{array}{c}\text { Akibat Potensi } \\
\text { Medication Error }\end{array}$ \\
\hline ama obat & \multirow{5}{*}{\multicolumn{2}{|c|}{$\begin{array}{l}\text { 0\% Salah pemberian obat } \\
0 \% \text { Salah pemberian bentuk } \\
\text { sediaan } \\
\text { 0\% Salah dosis obat (over } \\
\text { dose/ under dose) } \\
\text { 0,67 Salah pemberian jumlah } \\
\text { obat, lama penggunaan } \\
\text { obat salah. }\end{array}$}} \\
\hline $\begin{array}{l}\text { entuk } \\
\text { ediaan }\end{array}$ & & \\
\hline ekuatan & & \\
\hline ediaan & & \\
\hline amlah obat & & \\
\hline ituran & $14,67 \%$ & ah dosis sekali \\
\hline & & Im dan sehari (over \\
\hline enggunaan & & el under dose) \\
\hline
\end{tabular}

Data karakteristik pada Tabel 2 menunjukkan potensi medication error didapatkan dari perhitungan jumlah resep yaitu 150 terdapat 23 resep yang tidak lengkap. Apabila ketidaklengkapan pada salah satu persyaratan farmasetis maka dianggap sebagai resep yang berpotensi medication error. Kelengkapan farmasetis yang kebanyakan dituliskan oleh dokter adalah jumlah obat dan aturan dan cara pemakaian. Persyaratan farmasetis yang banyak tidak tercantum dalam resep adalah kebanyakan pada atura dan cara pakai penggunaan obat dalam resep yaitu 22 lembar resep.
Tabel 3. Karakteristik kelengkapan klinis

\begin{tabular}{|c|c|}
\hline $\begin{array}{l}\text { Kelengkapan } \\
\text { Resep }\end{array}$ & $\begin{array}{l}\text { Akibat Potensi } \\
\text { Medication Error }\end{array}$ \\
\hline epatan & $0,7 \%$ Salah pemberi \\
\hline ggunaan & $\begin{array}{r}21,33 \% \text { Salah } \\
\text { bentuk }\end{array}$ \\
\hline $\mathrm{roj}$ & $\begin{array}{l}\text { 0\% Salah dosis ob } \\
\text { dosel under do }\end{array}$ \\
\hline dikasi, & $\begin{array}{l}0 \% \text { Salah pemberian } \\
\text { jumlah obat, lama } \\
\text { penggunaan } \\
\text { salah. }\end{array}$ \\
\hline at. & $\begin{array}{l}0,53 \% \text { Salah dosis sekali } \mathrm{m} \\
\text { inum dan sehari (over } \\
\text { dosel under dose) }\end{array}$ \\
\hline $\begin{array}{l}\text { umlah obat }>7 \\
\text { tem }\end{array}$ & $\begin{array}{r}6,67 \% \text { Po } \\
\text { ex }\end{array}$ \\
\hline${ }_{3}$ imlah Antibiotika & $\begin{array}{r}0,7 \% \text { Polifarmasi, } \\
\text { extravagant }\end{array}$ \\
\hline
\end{tabular}

Potensi medication error yang dianalisis adalah temuan ketidaklengkapan resep pada pengkajian resep dengan checklist. Apabila ditemukan satu persyaratan saja tidak ada maka resep dianggap berpotensi terjadi medication error. Medication error yang dimaksud adalah kategori A yaitu kondisi atau peristiwa yang mempunyai kapasitas untuk menyebabkan medication error atau berpotensi medication error. Interaksi obat dikaji dengan cara melihat kombinasi obat dalam resep dan dilakukan pengkajian berdasarkan dengan referensi. Pada penelitian ini data yang memungkinkan untuk dianalisis hanya kesesuaian dosis obat dengan usia, waktu penggunaan obat dan interaksi obat secara literatur. Literatur yang digunakan untuk pengkajian resep persyaratan klinis adalah dari buku Drug Information Hanbook 26th edition 2016-2017 dan medscape.

Tabel 1 Tabel Temuan Resep yang berpotensi medication error

\begin{tabular}{lll}
\hline \multicolumn{4}{c}{ Interaksi Obat } \\
\hline Glimepirid + Propanolol efeknya & akan \\
meningkatkan efek hypoglikemi & & \\
Aspilet + NSAID Meloxicam efeknya & akan \\
meningkatkan resiko GI Bleeding & & \\
$\mathrm{K}$ Diklofenak + Aspilet efeknya & akan \\
meningkatkan resiko GI Bleeding & \\
$\mathrm{K}$ Diklofenak + Aspilet efeknya & akan \\
meningkatkan resiko GI Bleeding &
\end{tabular}

Furosemid + Dogoxin efeknya akan meningkatkan efek samping digoxin Klopidogrel + Aspilets efeknya akan meneingkatlan resiko GI Bleeding

Aspilet + Ketoprofen efeknya akan meningkakan resiko GI bleeding

Sumber: Data primer yang diolah, 2018 
Tabel 5. Tabel Temuan Resep yang berpotensi medication error Waktu penggunaan Obat

Omeprazol tidak ada signa $\mathrm{pc} / \mathrm{ac}$

Sukralfat tidak ada signa ac/ pc

Lanzoprazol tidak ada signa pc/ ac

Omeprazol dan sukralfat tidak ada signa pc/ac

Sumber: Data primer yang diolah, 2018

\section{Dosis}

Dosis alprazolam untuk usia 75 th diawali dengan $1 / 2$ dosis $=0,25 \mathrm{mg}$ tetapi dalam resep 1 dosis.

Berdasarkan data ini digunakan untuk tahapan define. Faktor penyebab medication error pada tahap pengkajian klinis pada resep ada beberapa hal. Persyaratan kelengkapan klinis terdiri dari 7 macam komponen persyaratan yang membutuhkan pengetahuan penulis resep yang berkaitan dengan ketepatan indikasi, dosis, waktu penggunaan obat, duplikasi, alergi, reaksi obat tidak diinginkan dan interaksi obat-obat dalam resep. Pengkajian resep inilah yang akan sangat berperan dalam mencegah terjadinya medication error. Kemampuan dan ketrampilan penulis resep dan penelaah resep sangat dibutuhkan dalam hal ini. Berdasarkan hal tersebut maka dibutuhkan sarana atau sistem yang cepat diakses sehingga dapat membantu supaya kesalahan dalam persyaratan klinis tidak terjadi dan pasien juga tidak menunggu terlalu lama untuk proses pengkajian klinis tersebut.

Pemilihan konsep six sigma untuk penerapan di Unit Farmasi Rawat Jalan karena six sigma mengandung unsur-unsur pemahaman pengukuran dan penyempurnaan yang berkesinambungan terhadap proses kegiatan demi kepuasan pasien terhadap kinerja Pelayanan resep, sehingga kemungkinan terjadinya penyimpangan dapat ditekan seminimal mungkin.

Berdasarkan temuan potensi medication error maka dibutuhkan suatu sistem yang digunakan untuk meminimalkan terjadinya medication error sehingga tujuan untuk meningkatkan mutu Pelayanan kefarmasian di Rumah Sakit yang berorientasi kepada keselamatan pasien tercapai.

1.Fase Define

Indikator checking adalah komponen kelengkapan resep yang dikaji dalam resep. Potensi medication error yang disebutkan adalah kejadian kondisi atau peristiwa yang mempunyai kapasitas untuk menyebabkan error atau berpotensi error apabila resep tidak lengkap pada komponen administatif, farmasetis maupun klinis.

Resep yang tidak lengkap banyak terjadi pada waktu penggunaan obat dikaji dengan melihat signatura, pada bagian ini terlihat aturan pakai obat sehari berapa kali dan aturan tambahan kapan minum obatnya seperti contoh pagi, siang, sore atau malam. Aturan yang dapat dilihat juga meliputi sesudah makan, sebelum makan, saat makan. Kesesuaian dosis persyaratan klinisnya ada juga yang tidak sesuai. Hal ini adalah terkait dengan kelengkapan farmasetis apabila dalam resep tidak disebutkan kekuatan sediaan maka akan berpotensi medication error yaitu berakibat dosis yang digunakan melebihi atau kurang dari dosis terapinya. Dari ketiga komponen kelengkapan resep untuk persyaratan klinis yang dikaji, interaksi obat juga ditemukan. Hal ini disebabkan karena persyaratan untuk interaksi obat adalah paling berpotensi medication error dan efeknya paling berbahaya jika tidak dikendalikan dengan baik. Interaksi obat merupakan perubahan efek obat utama oleh pemberian obat lain sebelumnya atau secara bersamaan. Persyaratan untuk pengkajian interaksi obat ini dinyatakan ada interaksi berdasarkan referensi baik sebagai interaksi obat major, moderate, atau minor pada kombinasi obat dalam resep.

\section{Fase Measure}

\section{Tabel . Hasil Konversi Nilai Resep Aktual (Yield), DPMO dan Sigma}

Pengkajian ield (\%)) efect DPMO Sigma Rang

$$
\text { Reser }
$$

(\%)

$\begin{array}{llllll}\text { Prescribing } & 96,49 \% & 1,17 \% & 117.000 & 1,565 & \text { III }\end{array}$

Administrasi

Prescribing $\quad 87,13 \% \quad 12,87 \% \quad 128.000 \quad 1,532 \quad$ IV

Farmasetis

$\begin{array}{llllll}\text { Prescribing } & 85,38 \% & 14,62 \% & 146.200 & 1,453 & \text { V }\end{array}$

Klinis

Transcribing 96,49\% $\quad 3,51 \% \quad 35.100 \quad 2.160 \quad$ II

$\begin{array}{lrrrrr}\text { Dispensing } & 99,42 \% & 0,58 \% & 5.800 & 4.020 & \text { I }\end{array}$

$\begin{array}{lllll}\text { Total } & 92,98 \% & 6,54 \% & 65.400 & 2,146\end{array}$

*Yield artinya resep yang tidak berpotensi medication error

*Defect artinya resep yang berpotensi medication error

Sumber: Data primer yang diolah, 2018

Tahap define sudah dilakukan mulai dari karakteristik temuan potensi medication error. Pengkajian resep adalah tahap pertama yang paling penting dalam Pelayanan kefarmasian. Masalahnya adalah apabila resep yang diterima tidak jelas dan tidak lengkap sesuai dengan penelusuran prosedur yang ada di rumah sakit tenaga kefarmasian akan tenaga kefarmasian harus menanyakan dan mengkonsultasikannya ke dokter penulis resep sesuai prosedur. Kegiatan ini untuk menganalisa adanya masalah terkait obat, bila ditemukan masalah terkait obat harus dikonsultasikan kepada dokter penulis resep. Apoteker harus melakukan pengkajian Resep sesuai persyaratan administrasi, persyaratan farmasetik, dan persyaratan klinis baik untuk pasien. Waste yang ditemukan adalah waiting, motion, transportation, overproccesing dan defect.

Data kelengkapan resep yang berpotensi menimbulkan medication error diatas setelah implementasi standar Pelayanan kefarmasian menunjukkan masih terdapat kesalahan dalam kelengkapan resep yang berpotensi terjadi medication error. Dari instumen identifikasi waste, ditemukan waste yang terkait dengan defect, motion dan waiting. Proses pengkajian resep dalam Pelayanan kefarmasian apabila terjadi ketidaklengkapan resep dan harus konsultasi 
menghubungi dokter atau pasien kembali lagi ke dokter untuk konfirmasi adalah suatu waste. Waste yang terjadi adalah waste of waiting yaitu apabila resep tidak lengkap maka Pelayanan resep akan tertunda karena tenaga kefarmasian harus mengkonfirmasi untuk menanyakan atau mengkonsultasikan ke dokter penulis resep.

3.Fase Analysis

Atribut-atribut Pelayanan resep yang diterima oleh pasien penting untuk ditingkatkan kualitasnya dengan tujuan untuk keselamatan pasien. Tahapantahapan pengkajian resep hingga dispensing yang mempunyai kinerja Pelayanan paling rendah atau tingkat sigma paling kecil. Pelayanan tersebut sebesar $20,35 \%$ dengan level sigma tersebut maka secara berurutan sigma dan temuan medication error adalah 1,886 mulai dari Prescribing klinis, Prescribing farmasetis, prescribing administrasi, transcribing, dan dispensing. Perbaikan pada fase prescribing dan transcribing sebenarnya sudah mulai diperbaiki dengan implementasi system informasi di Rumah sakit dengan adanya e-prescribing hanya saja belum diimplementasikan oleh seluruh prescriber sehingga masih terdapat beberapa angka temuan. Fase Prescribing klinis dapat diatasi dengan menambakan menu checking persyaratan klinis pada e-prescribing ataupun dengan akses aplikasi drug checker yang memadai untuk Tenaga Kefarmasian dan Prescriber. Pada Fase transcribing, dan dispensing tetap dibutuhkan proses pengecekan ulang dikarenakan pada saat jam pelayanan puncak jumlah resep akan meningkat drastis, tenaga kefarmasian tetap sehingga dibutuhkan tambahan tenaga kefarmasian dari bagian lain untuk membantu proses pelayanan di instalasi farmasi rawat jalan. Proses cek ulang sangat dibutuhkan juga faktor jumlah resep, varian obat, dosis dan bentuk sediaan sangat banyak sehingga faktor kesalahan masih dapat diatasi sebelum terpapar ke pasien. Kegiatan pengkajian resep yang harus dilalui sesuai dengan standar pelayanan kefarmasian adalah banyak skrining sehingga dibutuhkan waktu pengecekan yang tidak sedikit dan petugas penerima resep kadang tidak selalu Apoteker sehingga terkait dengan kepuasan pasien yaitu waktu tunggu yang lama. Maka untuk proses skrining dapat diatasi dengan meningkatkan pengetahuan Tenaga kefarmasian dan penulis resep/ prescriber. Akses untuk pengecekan interaksi obat dan kontraindikasi juga perlu diperbaiki dengan peningkatan kemudahan akses sehingga dapat menyingkat waktu skrining resep untuk mengurangi waktu tunggu pasien serta tetap menjaga obat yang diserahkan terhindar dari resiko medication error. Ketidaksesuaian dan kesalahan dalam peresepan dan pelayanan resep kebanyakan adalah kasus yang dapat dicegah (preventable). Strategi intervensi terutama difokuskan pada pelatihan dan penciptaan lingkungan kerja yang kondusif dan meminimalkan medication error. Harus ada intervensi yang bertujuan untuk meningkatkan pengetahuan dan pelatihan, dan mengurangi kompleksitas. [6]. Berdasarkan temuan potensi medication error maka dibutuhkan suatu sistem yang digunakan untuk meminimalkan terjadinya medication error sehingga tujuan untuk meningkatkan mutu pelayanan kefarmasian di Rumah Sakit yang berorientasi kepada keselamatan pasien tercapai.

4.Fase Improve

Nilai rata-rata kinerja Pelayanan resep di unit farmasi rawat jalan RSI Sultan Agung tanpa defect yaitu 92,98 artinya secara keseluruhan kinerja Pelayanan resep unit farmasi rawat jalan RSI Sultan Agung sebesar 6,54\% yang masih memberikan peluang munculnya ketidakpuasan pasien rawat jalan yang menebus resep. Sigma Nilai actual resep adalah 2,146 maka secara berurutan berdasarkan rangking sigma adalah Prescribing klinis, Prescribing farmasetis, prescribing administrasi, transcribing, dan dispensing. Pengetahuan dari Apoteker dalam melakukan pengkajian persyaratan resep terutama fase farmasetis dan klinis juga perlu ditingkatkan dalam menganalisis ketepatan indikasi, dosis, waktu penggunaan obat, duplikasi, alergi, reaksi obat tidak diinginkan dan interaksi obat-obat dalam resep.

\section{Fase Control}

Instalasi Farmasi RSI Sultan Agung telah mempunyai SPO (Standar Pelayanan Operasi) secara lengkap terkait Pelayanan kefarmasian termasuk SPO Pelayanan resep baik racikan dan jadi, maka bentuk pengendalian dapat dilakukan dengan cara pemeriksaan berkala untuk meyakinkan bahwa prosedur yang benar telah diikuti. Jika tidak sesuai dengan prosedur, maka harus ada tindakan korektif untuk mengatasi masalah dan membawa proses tersebut kembali ke dalam kinerja yang stabil. Karena fase pengendalian berfokus pada bagaimana menjaga perbaikan agar terus berlangsung secara stabil. Tindakan- tindakan perbaikan yang dilakukan adalah dengan pemanfaatan technology information system memanfaatkan database identitas pasien dan database obat sehingga membantu dokter dalam penulisan obat yang benar dan sesuai dengan syarat kelengkapan resep. Berdasarkan data yang didapatkan pada alur Pelayanan pasien rawat jalan dapat diambil langkah perbaikan dengan menganalisis titik kritis pada Pelayanan kemudian benang merahnya yaitu pada saat pasien registrasi, keluarga ataupun pasien sudah menjawab pertanyaan tentang identitas diri baik melalui kartu ataupun lisan (bagi pasien baru). Dari beberapa langkah yang sama tujuan dan obyeknya ini sebenarnya dapat dipermudah dan dipersingkat jika ada database pasien yang dapat diakses mulai dari registrasi, poliklinik, dokter, instalasi farmasi hingga pada saat pembayaran. Berdasarkan hal tersebut maka dibutuhkan sistem informasi rumah sakit yang terintegrasi. Masalah ketidaklengkapan peresepan yang ditulis oleh dokter, kesalahan dalam penentuan dosis obat yang dapat berpotensi menimbulkan medication error. Berdasarkan data tersebut, penulis membuat sistem yang dapat digunakan untuk mengotomasi pembuatan resep obat beserta dosis obat yang dibutuhkan serta dapat memberikan rekomendasi alternatif jenis obat. Dapat mengurangi kesalahan pembuatan resep obat akibat resep yang ditulis dengan tangan. 
Menghemat waktu, tenaga, dan biaya dalam proses Pelayanan kefarmasian.

\section{KESIMPULAN}

Hasil konversi rata-rata nilai kinerja pelayanan resep nilai Yield $=92,98 \%$, defect $=6,54 \%$, artinya kinerja pelayanan resep unit farmasi rawat jalan RSI Sultan Agung tanpa potensi medication error adalah sebesar $92,98 \%$ yang masih memberikan peluang Hasil konversi rata-rata nilai kinerja pelayanan resep nilai Yield $=92,98 \%$, defect $=6,54 \%$, artinya kinerja pelayanan resep unit farmasi rawat jalan RSI Sultan Agung tanpa potensi medication error adalah sebesar $92,98 \%$ yang masih memberikan peluang munculnya potensi medication error sebesar 6,54\%. DPMO = 65.400 dengan sigma 2,146 maka masih dibutuhkan perbaikan pada kinerja pelayanan resep sehingga dapat memenuhi keinginan pasien. Berdasarkan Level sigma secara berurutan peningkatan kinerja pelayanan resep adalah pada Prescribing klinis, Prescribing farmasetis, prescribing administrasi, transcribing, dan dispensing untuk peningkatan keselamatan pasien

\section{UCAPAN TERIMA KASIH}

Terima kasih diucapkan pada Akademi Farmasi Nusaputera dan Kemenristek Dikti.

\section{REFERENSI}

[1] Gaspersz, Vincent, 2007, Lean Six Sigma for manufacturing and service Industries, PT. Gramedia Pustaka Utama, Jakarta, ISBN97922-2559-5

[2] Hartono, G., Putro, T.N., Farhan, F., dan Fitrianingtyas, R., 2010. Analisis Kinerja Proses dan Produk Dengan Pendekatan Metodologi Six Sigma (DMAIC) untuk Produk Teh Botol Pada PT XYZ. Industrial and Systems Engineering Assessment Journal (INASEA), 11.

[3] Sunariningtyas, 2014. Studi Kualitas Pelayanan Rawat Inap Rumah Sakit dengan Menggunakan Metode Six Sigma (Studi Kasus : Rumah Sakit Dedy Jaya Brebes) 2: 114

[4] Menkes, R., 2016. Permenkes No 72 Tahun 2016 Standar Pelayanan Kefarmasian di Rumah Sakit.

[5] Sidhh, M.M., Gadekar, G., Soni, G., dan Jain, R., 2013. Lean Six Sigma Approach for Performance and Business Performance. Research India Publications, , Global Journal of Management and Business Studies. 3: 589594

[6] Velo, G.P. dan Minuz, P., 2009. Medication errors: prescribing faults and prescription errors. British Journal of Clinical Pharmacology, 67: 624-628 